\title{
Dermatolojide Plateletten Zengin Plazma Tedavisi
}

\author{
Platelet Rich Plasma Treatment in Dermatology
}

Selami Aykut Temiz,

Recep Dursun ${ }^{1}$,

${ }^{1}$ Necmettin Erbakan Üniversitesi, Meram Tıp Fakültesi, Dermatoloji Anabilim Dalı, Konya, Türkiye

Geliş Tarihi/Received: 6 Ekim 2019

Kabul Tarihi/Accepted: 11 Ocak 2020

Yazışma Adresi: Selami Aykut Temiz, Necmettin Erbakan Üniversitesi, Meram Tıp Fakültesi, Dermatoloji Anabilim Dalı, Konya, Türkiye

e-mail: aykutmd42@gmail.com

\section{ORCID}

Selami Aykut Temiz

https://orcid.org/0000-0003-4878-0045

Recep Dursun

https://orcid.org/0000-0002-1279-574X

\begin{abstract}
Öz
Plateletten zengin plazma tedavisi, son zamanlarda kullanımı giderek artan, kanın santrifüj edilmesiyle elde edilen ve yüksek konsantrasyonda platelet içeren plazma bileşenidir. İlk olarak 1987'de açık kalp ameliyatlarını takiben homolog kan ürünlerinin transfüzyonunu azaltmak için kullanılmıştır. Günümüzde dermatolojinin yanısıra ortopedi, fizik tedavi, plastik cerrahi, kalp damar cerrahi, maksillofasiyal cerrahi, üroloji ve oftalmoloji gibi birçok alanda kullanımı giderek artmaktadır. Dermatolojide de giderek artan sıklıkta birçok farklı endikasyonda kullanılmaktadır. Biz bu derleme çalışmamızda dermatoloji ve kozmetik dermatoloji alanında PRP'nin endikasyonları ve genişleyen yeni kullanım alanlarını mevcut literatür eşliğinde irdeledik. Özellikle yeni ve merak uyandıran kullanım alanlarına değinmeye çalıştık. Çalışmalardan elde edilen sonuçlar umut vermekte ve her geçen gün yeni bir endikasyona işaret etmektedir. Fakat çalışmalarda genellikle uygulama standardizasyonu ve hasta sayısının azlığı sınırlayıcı etkileri oluşturmaktadır. Plateletten zengin plazmanın kesin endikasyonlarını belirlemeden önce, uygulamaların standardizasyonu ve geniş hasta popülasyonları üzerinde yapılmış kontrollü çalışmalara ihtiyaç duyulmaktadır.

Anahtar Kelimeler: Plateletten zengin plazma, dermatoloji, kozmetik dermatoloji

\section{Abstract}

Platelet-rich plasma has become increasingly popular in recent years, and it is a plasma component that contains a high concentration of platelets, which is obtained by centrifugation of blood. It was first used in 1987 to reduce the transfusion of homologous blood products following open heart surgery. In recent years, in addition to dermatology, the use of platelet-rich plasma has been increasing in many medical branches such as orthopedics, physical therapy, plastic surgery, cardiovascular surgery, maxillofacial surgery, urology and ophthalmology. It is increasingly used in dermatology for many different indications. In this review, we examined the indications of PRP in the field of dermatology and cosmetic dermatology and the expanding new applications in the current literature. In particular, we tried to address new and intriguing indications for its use. The results obtaine in the studies give hope and indicate a new indication every day. However, in studies, the lack of application stand and the low number of patients are seen as limiting effects. Before determining the exact indications of the platelet-rich plasma, standardization of applications and controlled studies on large patient populations are needed.
\end{abstract}

Key words: Platelet-rich plasma, dermatology, cosmetic dermatology
Atıf yapmak için: Temiz SA, Dursun R. Dermatolojide Plateletten Zengin Plazma Tedavisi. Selcuk Med J 2020;36(3): 274-281
Açıklama: Yazarların hiçbiri, bu makalede bahsedilen herhangi bir ürün, aygıt veya ilaç ile ilgili maddi çıkar ilişkisine sahip değildir. Araştırma, herhangi bir dış organizasyon tarafından desteklenmedi. Yazarlar çalışmanın birincil verilerine tam erişim izni vermek ve derginin talep ettiği takdirde verileri incelemesine izin vermeyi kabul etmektedirler. 


\section{GíRiş \\ Plateletten Zengin Plazma}

Plateletler, kan pıhtılaşma mekanizmasında rolü ile bilinen, granüllü yapıda ve renksiz hücre parçaları olup, kemik iliğindeki megakaryositlerin sitoplazmik parçacıklarıdır (1). Plateletten zengin plazma (Platelet-rich plazma, PRP), son yıllarda kullanımı giderek artan, venöz tam kanın santrifüjü ile elde edilen ve yüksek konsantrasyonda platelet içeren plazma bileşenidir (2). Plateletten zengin plazma uygulamasında platelet sayısı için belirgin bir

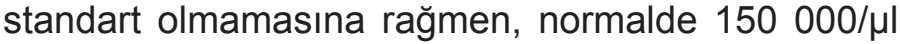

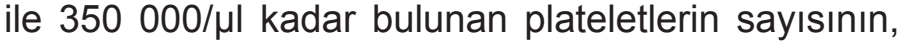
$5 \mathrm{ml}$ plazmada 1500 000/ul üzerine çıktığı zaman etkili olduğundan bildiren yayınlar mevcuttur (3). İlk kez 1987 yılında kalp cerrahilerini takiben homolog kan ürünlerinin transfüzyonunu azaltmak için kullanılmıştır (4). Günümüzde dermatolojinin yanısıra ortopedi, fizik tedavi, plastik cerrahi, kardiyovasküler cerrahi, maksillofasiyal cerrahi, üroloji ve oftalmoloji gibi birçok alanda kullanımı giderek artmaktadır (5). Dermatolojide de giderek artan sıklıkta birçok farklı yeni endikasyonla kullanılmaktadır (6).

\section{Plateletten Zengin Plazma Hazırlanışı}

Plateletten zengin plazma, steril koşullarda ve laboratuvar ortamlarında hazırlanmalıdır. PRP hazırlama işlemi hastadan kan alınması ile başlar. Kan alınması işleminde 18-20 gauge gibi geniş iğne uçlarının kullanılması plateletlerin daha az travmatize edilerek, uygulama öncesinde inaktif durumda olmasını sağlamak açısından önemlidir. Pıhtılaşmış olan kanda, plateletler oluşan pıhtının bir parçası olduğu için ayrıştırılma imkanı yoktur. Bu nedenle, PRP hazırlanırken santrifüj işlemi yapılmadan önce alınan kan tüpüne genellikle sitrat katılarak iyonize kalsiyum bağlanır ve pıhtılaşma kaskadı inaktive edilir (7). PRP hazırlanması sırasında, PRP'nin içeriğine etki eden birçok faktör olduğu düşünülmektedir; kullanılan yönteme ek olarak, hastanın bizzat kendi kanının özelliklerinden dolayı farklılıklar görülebilir (8). Standardize edilmiş ve genel kabul görmüş bir PRP hazırlama yöntemi yoktur. Manuel şekilde hazırlanabileceği gibi, FDA (Food and Drug Administration) onaylı hazır ticari PRP kitleri de kullanılabilmektedir (9). Günümüzde tanımlanmış başlıca dört temel plateletten zengin plazma ürünü hazırlama metodu vardır, bu metodlar sırasıyla: (10)

1) Pure Platelet Rich Plasma (P-PRP): Bu yöntemde, lökositten tamamen arındırılmış saf platelet elde edilir. Bu yöntemin en önemli farklarından biri plazmaferez gibi 'hücre ayırıcılar' kullanılmasıdır. Bu sayede PRP içeriğindeki lökosit sayısı sıfır veya inmal edilebilecek düzeyde çok düşüktür. P-PRP yönteminin en önemli dezavantajları, diğer yöntemlere göre uygulanmasının zor ve çok daha maliyetli olmasıdır (10).

2) Lökosit ve Platelet Rich Plasma (L-PRP): Sitratlı bir tüpe venöz kan alındıktan sonra, basit bir santrifüj yapılması ile elde edilir. Santrifüj edilen tüpün orta kısmında (buffy coat) plateletlerle birlikte lökositler bulunur. L-PRP yönteminin elde edilmesi ve uygulamasının pratik olması sık kullanılmasını sağlamaktadır.

3)Pure Platelet Rich Fibrin (P-PRF): Bu yöntem L-PRP yöntemine benzemekle beraber, ilk santrifüj sonrasında, eklenen $\mathrm{CaCl}$ (Kalsiyum klorür) ile birlikte ikinci santrifüj sonrasında stabil platelet-fibrin pıhtı elde edilmesine dayanır. Fibrin olduğu için sadece açık yüzeylere uygulanabilmektedir.

4) Lökosit ve Platelet Rich Fibrin (L-PRF): Bu yöntemde, alınan kan örneklerine herhangi bir antikoagülan veya ayırıcı kullanılmadan düşük süratte hemen santrifüj uygulanır. Oluşan üç farklı katman, sırasıyla; asellüler plazma, plateletten zengin fibrin ve en altta eritrosit tabakadır. L-PRF yöntemi basit ve ucuz bir yöntem olmakla beraber, sadece açık yüzeylere uygulanması sebebiyle kullanım alanları dardır.

L-PRP dermatolojide en sık kullanılan PRP yöntemidir (11). Sekiz ile 15 dakika arasında 30003500 devir/dakika ile santrifüj edildiğinde tam kanın bileşenleri yer çekimine göre üç katmana ayrılır: üst katman (plazma), orta katman (platelet ve lökositler) ve en alt katman (eritrositler) (12). Buffy coat olarak adlandırılan bu orta kısım yaklaşık 5-6 ml kadar olup, direk enjektör ile alt ve üst kadmana karıştırılmadan alınır. Elde edilen bu plateletten zengin plazma, tedavi edilecek cilt bölgesine mezoterapi, intralezyonel veya dolgu yöntemleriyle enjekte edilebilir. Buffy coat ve plazma kısmına ikinci bir santrifüj işlemi uygulanarak PRP ve plateletten fakir plazmanın (platelet poor plasma-PPP) daha ileri ayrışma sağlanabileceğini belirten bazı otörler mevcuttur (13). PRP uygulamasından önce plateletlerin aktive edilip edilmemesi gerektiği ve aktivasyon için hangi agonistin kullanılacağı konusunda fikir birliği yoktur. Bazı otörler trombositleri trombin veya kalsiyum ile aktive ederken, diğerleri daha iyi sonuçların alındığını iddia ederek daha önce aktive olmayan inaktif plateletleri uygular (14). Aktive plateletlerden büyüme faktörlerinin salınımının ilk on dakika içinde başlayıp bir saat içinde tamamlandığı düşünülmektedir. Bu 
nedenle hazırlanan PRP'nin on dakika içinde tedavi alanına uygulanması önerilir (15). Fakat 24 saat içinde kullanılabileceği de söylenmektedir. Uygulama süresi ve etki kaybı arasında literatürde kesin bir kanıt yoktur (15).

\section{Plateletten Zengin Plazma Etki Mekanizması}

Esas olarak hemostazdaki rolleri ile bilinen plateletler, periferik kandaki küçük ve çekirdeksiz pulcuklardır. Periferik kana yeni çıkan plateletler 7-10 gün sonra retiküloendotelyal sistemdeki makrofajlar tarafından parçalanırlar (16). Plateletlerde alfa, yoğun kor (delta) ve lizozomal (lambda) olmak üzere üç adet granül mevcuttur (17). Lizozomlar proteolitik ve asit hidrolik enzimleri, yoğun kor granüller ise serotonin ve adenozin difosfat gibi platelet agonistlerini intiva etmektedir (18). Büyüme faktörleri alfa granüllerde bulunmaktadır. Bir trombosit ortalama 50-80 adet alfa granül içermektedir. Bu granüller PDGF (platelet kaynaklı büyüme faktörü), TGF- $\beta 1-2$ (dönüştürücü büyüme faktörü- $\beta$ ), IGF (insülin benzeri büyüme faktörü), EGF (epitelyal büyüme faktörü), VEGF (vasküler endotelyal büyüme faktörü), mitojenik büyüme faktörleri,osteonektin, osteokalsin, fibrinojen, fibronektin, trombospondin gibi koagülasyon faktörleri ve bazı adheziv faktörler gibi biyoaktif proteinleri içerirler (19).

PRP içerdiği yüksek trombosit konsantrasyonu sayesinde hiperfizyolojik miktarlarda büyüme faktörü içermektedir. PRP, tam kan ile karşılaştırıldığında TGF-ß'yı 7 kat,EGF'yi 10 kat, PDGF'yi 30 kat daha fazla içermektedir (18). Başlıca PDGF, VEGF, TGF- $\beta$, EGF ve IGF olmak üzere birçok büyüme faktörü plateletlerin alfa granüllerinden salınmaktadır (15). TGF- $\beta$ özellikle fibroblastları aktive ederek hücre bölünmesine ve kollajen üretilmesine neden olmakta ve PRP'nin birçok etkisinden sorumlu tutulmaktadır (15). Aynı zamanda TGF-ß’nın inflamasyonu önleyici ve immundisregülasyonu düzenleyici etkileri de mevcuttur (21). Plateletler, trombin ileaktive olmalarıyla şekil değiştirerek psödopod adı verilen uzanımlar gösterirler. Aktivasyonu takiben a-granüllerinde bulunan pıhtılaşma ve büyüme faktörleri ortama salınırlar. Membran reseptörlerine bağlanan büyüme faktörleri, çeşitli biyolojik yolakların başlatıcısı olan küçük peptid moleküllerdir. Büyüme faktörlerinin hücre regülasyonunda, differansiasyonda, proliferasyonda, kemotaksiste, anjiogenezde ve matriks sentezindeki etkileri yara iyileşmesi ve onarım sürecinde kritik rol oynamaktadır. Ek olarak, dens granüllerde bulunan serotonin, adenozin, dopamin, kalsiyum, histamin, ATP, ADP ve katekolamin gibi diğer biyoaktif moleküller de doku yenilenmesinde rol almaktadır (22). PRP'nin içeriğindeki az miktardaki lökosit, antikor proteolitik enzimler sayesinde fizyolojik antibakteriyel etki gösterirdiği düşünülmektedir. Plazma içeriğinde hormonlar, biyotransforme vitaminler ve diğer besin öğelerini de içermektedir (17).

Plateletlerin bir diğer önemli özelliği de virüslere, bakterilere, mantar ve hatta protozoalara karşı da önemli rol oynamalarıdır. Alfa granüller, antimikrobiyal özellikli CXCL4 (Kemokin ligand 4), CXCL7(Kemokin ligand 7) ve CCL5 (Kemokin ligand 5) ile C3 (Kompleman 3) ve C4 (Kompleman 4) prekürsörlerini de taşır (23). Görüldüğü gibi plateletlerin kanamayı önleme ve durdurma (hemostaz) temel bilinen etkilerine ek olarak birçok fonksiyon ve özelliği bulunmaktadır. Plateletlerin biyoteknolojik önemine dair çalışmalar, son yıllarda giderek artmıştır (21). Özellikle platelet ve lökositin minimal olduğu büyüme faktörlerinin daha yoğun olduğu materyal ve kültür geliştirme çalışmaları gündeme gelmektedir (21).

\section{Plateletten Zengin Plazma Kullanım Avantajları}

Yüksek düzeyde tolere edilebilmesi, uygulama kolaylığı,sağlanan etkinin görece olarak uzun olması, tedavi sürecinin güvenli olması, yeni ve doğal kollajen yapımının biyolojik olarakstimüle edebilmesiaçısından birçok üstünlüğü bulunur (20). Yöntemin en önemli avantajlarından biri de hastanın kendi kanından elde ediliyor olması ve alerji riskinin en düşük seviyede olmasıdır. Otolog olduğu için rejeksiyon riski olmadığı kabul edilmektedir. Olağan cerrahi prosedürlere dikkat edildiği takdirde, muhtemel enfeksiyonlar (Hepatit B, Hepatit C, Sifiliz, HIV vb.) açısından güvenlidir (3).

\section{Plateletten Zengin Plazma Kontrendikasyonları}

PRP'nin barındırdığı yüksek orandaki büyüme faktörleri nedeniyle maligniteye neden olup olmayacağı konusunda tartışmalar yapılsa da, klinik pratikte malignite ilişkisine dair veri saptanamamıştır (24). Bazı platelet bozuklukları (PRP'nin yüksek platelet konsantrasyonunu bozmakta), ciddi trombositopeni, hipofibrinojenemi, hemodinamik dengesizlik, sepsis, antikoagülan tedavi alıyor olmak, akut/kronik infeksiyonlar, mevcut kanser hastalığı ve kronik karaciğer patolojisi olan hastalarda PRP uygulaması önerilmemektedir (20). Mevcut otoimmun hastalığı olanlarda PRP uygulaması tartışmalıdır (20). Plateletten Zengin Plazma Komplikasyonları

PRP uygulama alanında hassasiyet, kaşıntı, yanma, ağrı, eritem, ekimoz, küçük hematomlar, sekonder enfeksiyonlar ve allerjik reaksiyonlar görülebilmektedir (25). Uygulama öncesinde hastanın dinlenmiş olarak gelmesi tercih edilir, uykusuz ve alert 
olması hastada ağrı eşiğini düşürebilmektedir. Yine üç gün önceden alkollü içecekler, ginko biloba, yeşil çay, kan sulandırıcı ilaçlar (rivaroksaban, heparin, klopidogrel, aspirin vs.) ve non-steroid anti-inflamatuar ilaçlar kesilmelidir. PRP tedavisi öncesi topikal anestezikler ağrı ve hassasiyeti azaltabilmektedir. Uygulama sonrası 24 saat banyo yapılmaması da enfeksiyöz riskleri azaltabilmektedir (25).

\section{Plateletten Zengin Plazma Dermatolojide Kullanım Alanları Yara İileşmesi}

Yara iyileşme sürecinde trombositler oldukça önemlidirler. Trombositler yara iyileşmesinin doğal süreci için gerekli olan büyüme faktörleri açısından oldukça zengin bir kaynaktır. Pıhtı oluşumu, lokal kan ve lenf kaybını durdurmaya ilaveten yara iyileşmesini tetikleyen büyüme faktörleri ve sitokinleri de salgılarlar (26). PDGF, fibroblastlar ve düz kas hücreleri için güçlü bir mitojendir ve yara iyileşmesinin her üç fazında da (anjiyogenez, fibröz doku oluşumu ve yeniden epitelizasyon) rol oynar (26). Kemik greftlerinde, doku genişletilmesinde, deri greftlerinin alıcı ve verici bölgelerinde, deri flaplarında, herni onarımında ve mammoplastide güvenle uygulanır (27).

Kronik iyileşmeyen ülserlerin tedavisinde epitelizasyonu hızlandırmak için plateletten zengin plazmanın kullanılabileceği ilk olarak 2004 yılında bir çalışmayla ortaya konmuştur (28). Sonraki yıllarda bunu diyabetik ülser gibi pek çok kronik ülsere lezyonda PRP'nin kullanımını gösteren çalışmalar izlemiştir (29,30). 2016 yılında yayımlanan metaanaliz ise PRP'nin kronik yaralarda etkinliğini kesin söyleyememiştir (31). Ancak yine de destekleyici verilerin olması, yan etkilerinin kısıtlı olması ile gelecekte umut verici bir tedavi olarak öngörülmüştür (31).

\section{Androgenetik Alopesi}

PRP, cells-katenin transkripsiyonel aktivitesinin düzenlenmesi yoluyla kök hücrelerin kıl folikül hücrelerine farklılaşmasını uyarabilmektedir. Ek olarak,içerdiği FGF-7 (fibroblast büyüme faktörü-7) sayesinde saç büyüme döngüsünün anajen fazını uzattığı ve apoptozu inhibe ederek hücre sağkalımını arttırdığı bilinmektedir. Ayrıca, anjiyojenik potansiyele sahip olan VEGF ve PDGF seviyelerinin yükselmesiyle perifoliküler vasküler pleksusun artması saç folikülleri daha çok kanlanmaktadır (32). Alopesiler, PRP'nin günlük pratikte en sık kullanıldığı alanlardandır. Minimal invazif ve güvenilir bir işlem olması nedeniyle PRP androgenetik alopesi tedavisinde de tercih edilmektedir. Uygulama sıklığı 2-4 hafta olacak şekilde
6-8 seans gibi uygulamalar tercih edilebilmektedir (33). Uygulama sayısı ve sıklığı, santrifüj yöntemleri, enjeksiyon bölgeleri ve verilmesi gereken PRP miktarı ile ilgili standart protokoller bulunmamaktadır (32). Son yıllarda otolog PRP gibi homolog PRP uygulamasının da kullanılabileceği gösterilmiş, Ince ve ark. (32) yaptığı çalışmada homolog PRP kullanımınında otolog PRP'ye oranla daha iyi yanıt sağladığı saptanmıştır. PRP'nin dermal papillada hücrelerinin çoğalmasını indüklediği ve anagen fazı uzattığı in vitro çalışmalarda gösterilmiştir (34). Ek olarak, saç transplantasyonunda bazı uygulamalarda nakil öncesinde ve cerrahi sonrası dönemde yapılan PRP tedavileriyle başarı oranını artırılabileceği belirtilmiştir (35).

2018 yılında tüm çalışmaların incelendiği metaanalizde PRP tedavisinin androgenetik alopeside istatistiksel olarak anlamlı katkısından bahsedilmiştir. Fakat 2019 yılında Lotti ve ark. tarafından yayınlanan meta-analizde ise sadece koşulları (randomize çift kör, kontrol grubu olan vs.) sağlayan çalışmalar incelenmiş ve androgenetik alopeside PRP tedavisinin başarısından söz etmek için henüz erken olduğu bildirilmiştir (36). PRP'nin günümüz pratiğinde en sık kullanımda olduğu androgenetik alopesi de halen randomize kontrollü ileri klinik araştırmalara intiyaç duyulmaktadır.

\section{Akne Skarları}

TGF- $\beta$ fibroblastları aktive ederek bağ dokusu hücre sayısını arttırmaya ve kollajen üretilmesine neden olur (37). Yine içerdiği büyüme faktörleri ile dermal rejenerasyonu arttırarak skar dokusunun azalmasına katkı sağlar (37). PRP kullanımı kontrollü olmayan 23 olguluk çalışmada akne skarlarında anlamlı etkinlik gösterdiği bildirilmiştir (37). Mikroiğneleme sistemi ve PRP'nin kombine edildiği bir çalışmada ise kombinasyonun tek başına mikroiğnelemeden daha iyi olduğu gösterilmiştir (38). 2018 yılında yapılan meta-analizde, akne skarlarında PRP'nin anlamlı derecede katkı sağladığı ve kombine tedavilere de uygun olduğu gösterilmiştir (39).

\section{Deri Rejüvenasyonu}

PRP'nin içerdiği büyüme faktörleri ve TGF- $\beta$ sayesinde fibroblastik aktivite artışı ve öncelikle kollajen olmak üzere diğer matriks proteinlerinin sentezinde artış etkisinden dolayı cilt gençleştirmede kullanılabileceği düşünülmüştür (40). Lazer yöntemlerine PRP'nin eklenmesi hem yan etkileri azaltma hem de sonuç açısından katkı sağlamaktadır (41). Etkinlik artışı, her iki yöntemin birlikte sinerjistik etkisine bağlanabilir. Yine PRP'nin antienflamatuar 
etkinliğinin de lazer tedavilerinin yan etkilerini azalttığı düşünülebilir (41). Fraksiyonel ablatif karbondioksit lazer sonrasında topikal veya intradermal PRP uygulamalarının arasında anlamlı bir fark izlenmemiştir (42).

\section{Alopesi Areata}

PRP içerdiği büyüme faktörlerinin, anjiyogenez, çoğalma ve saç foliküllerinde farklılaşmayı uyarması, anajen fazı artırması, saç büyümesini teşvik etmesi ve esas olarak lokal antiinflamatuvar etkisi sebebiyle alopesi areatada etkili olabileceği düşünülmüştür (43). İmmunsüpresan etkili TGF- $\beta$ içeriği sayesinde alopesi areatadaki immündisregülasyonu geri çevirebileceği ileri sürülmüştür (43). 45 hasta üzerinde yapılan çalışmada bir ay ara ile üç kez uygulanan PRP'nin intralezyonel triamsinolon asetonide göre daha etkili olduğu saptanmıştır (44). Alopesi areata'da PRP tedavisi çalışmaları henüz çok yeni olup birkaç çalışmadan genel veri elde etmek kolay olmamaktadır, bu konuda ileri kontrollü klinik çalışmalara intiyaç vardır.

\section{Melazma}

TGF- $\beta 1$ 'nın melanogenezisi inhibe edici özelliği nedeniyle TGF- $\beta 1$ 'den oldukça zengin olan PRP'nin melazmada kullanılabiliceği düşünülmüştür (45). EGF'nin melanin sentezinin inhibe edilmesine, PDGF stimülasyonunun da kollajen sentezi artışı ile cilt hacmindeki artışa neden olduğu görüşü vardır (45). Bir başka görüş de PRP'nin içerdiği multipl büyüme faktörleri ile melanogenezi indüklediği ve pigmentasyonu arttırabileceğidir (46). Hatta bu etkisi ile vitiligoda kullanımını gündeme getirmiştir (47). Yine anjiyojenik potansiyele sahip olan yüksek VEGF ve PDGF seviyeleriyle vasküler pleksusu arttırmasının özellikle melazmanın vasküler yapısını arttırıp artırmayacağı tartışma konusudur (46). 2018 yılında yayınlanan, 33 hastanın alındığı klinik çalışmada PRP'nin melazmada etkinliği gösterilmiştir (48). Melazma ile benzer olarak fotoyaşlanmada da etkili olduğundan bahseden çalışmalar mevcuttur (49).

Stria

Epidermal atrofinin eşlik ettiği dermal sikatris dokuları olan strialarda, günümüzde mevcut tedaviler genellikle yeterince başarılı değildir (50). PRP fibroblast büyümesini uyarır ve fibroblastlarda tip I kollajen ve metaloproteinaz proteinlerinin (MMP) ekspresyonunu indükler. Metalloproteinaz proteinleri, yenileriyle değiştirilen eski ve bozulmuş kolajenlerin temizlenmesine katılmaktadır. Bu nedenle PRP, Ekstrasellüler matriksin yeniden biçimlenmesini ve kollajen ve elastik lif oluşumunu indükler (51).
Tek başına mikrodermabrazyon, tek başına PRP ve kombine tedavinin etkinlikleri karşılaştırılan bir çalışmada en iyi sonuçlar kombine tedaviden alınırken tekbaşınaPRPtedavisitekbaşına mikrodermabrazyon tedavisinden daha etkili bulunmuştur (52). Yine son yıllarda PRP'nin topikal tretinoin tedavisinde de daha etkili olduğu gösterilmiştir (53). Tedavisi zor olan bu grupta PRP umut verici gözükmektedir. Yine de stria tedavisinin karmaşık ve kompleks olduğu bilinmelidir. Vitiligo

PRP'nin repigmentasyondaki etkisinin, mezenkimal kök hücrelerin melanositlere farklılaşmasına uyarılmasından kaynaklanıp kaynaklanmayacağı tartışmalıdır. PRP'nin büyüme faktörlerinden sitokin salınımını baskılayıp inflamasyonu sınırlandırarak melanositlerin apoptozunu sınırlandırdığı bilinmektedir, bu etkinin melanositler üzerindeki esas etki olduğu düşünülmektedir (54). 2011 yılında vitiligoda PRP'nin kullanımı ile ilgili ilk çalışma yapılmış, ve bu çalışmada PRP uygulaması vitiligo tedavisinde etkili bulunmamıştır (54). Bir başka çalışmada PRP uygulamasının dbUVB ile birlikte kullanıldığında etkinliği arttırdığı ve kümülatif dozu azalttığı gösterilmiştir (55). Yine PRP'nin vitiligoda fraksiyonel lazer tedavisine de kombine edilmesiyle etkinliği artırdığı gösterilmiştir (56). Vitiligo tedavisinde PRP çok yeni bir görüş olup, klinik çalışmaları çok az sayıdadır ve bu nedenle henüz görüş birliği yoktur.

\section{Pemfigus vulgaris}

Yara iyileşmesindeki olumlu etkileri PRP'nin pemfigusun dirençli ve kronik lezyonlarında kullanılabileceğini düşündürmüştür. İlginç bir şekilde, TGF- $\beta$ ' nın T regülatuar ve diğer $T$ helper hücreleri etkileyerek inflamasyon ve otoimmüniteyi önlediği gösterilmiştir (57). Pemfigusta ilk çalışma 2015 yılında yapılmış ve PRP'nin dirençli pemfigus vulgaris oral lezyonlarında etkin olduğu gösterilmiştir (57). Yapılan başka bir çalışmada da Pemfigus vulgarisin oral lezyonlarında intralezyonel triamnisolon asetonid ile PRP'nin arasında istatistiksel fark görülmemiştir (58). Fakat bu çalışmalar incelendiğinde metodolojik olarak sorunlu olduğu, sistemik olarak tedavisi devam eden olguların kontrol gruplarının olmadığı gözlenmiştir.

\section{Liken Planus, Liken Planopilaris, Liken Sklerozis}

PRP son yıllarda anlaşılan lokal antienflamatuar etkilerinden faydalanmak amacıyla birçok dermatozda denenmeye başlanmıştır. Dirençli bir oral liken planus olgusunda PRP'nin etkinliği gösterilmiştir (59). Yine liken planopilariste de olgu sunumlarında PRP'nin etkin ve güvenilir olduğu gösterilmiştir (60). Fakat bu konularda yapılmış çalışmaya rastlanılmamıştır, 
sadece olgu sunumları mevcuttur. Liken sklerozisde de olgu sunumlarına ek olarak 2019 yılında bir çalışmada PRP'nin etkinliğinden bahsedilmiştir (61).

\section{Psöriasis Vulgaris}

PRP, kemokin transaktivasyonunu ve CXCR4 reseptör ekspresyonunu inhibe ederek kemotaksiyi azaltır, böylece muhtemelen lokal enflamasyonu kontrol eder (62). Psöriasis vulgariste metotreksat ve PRP kombinasyonu, metotreksat monoterapi ile karşılaştırılmış ve etkili bulunmuştur (62).

\section{Sonuç}

Bu derlemeyle mevcut literatür eşliğinde PRP'nin dermatolojik hastalıklarda kullanım alanlarını incelemeye çalıştık. Otolog olması, alerjik reaksiyona yol açmaması, kolay elde edilebilmesi, etkinliği ve muhtemel enfeksiyonlar açısından güvenli olması ile PRP kullanım alanlarını gün geçtikçe artırmaktadır (6). Son yıllarda PRP,lokal antienflamatuar ve otoimmunite engelleyici etkilerinin anlaşılmasıyla bir çok dermatozda tedavi umuduyla denenmeye başlanmıştır $(47,55,57,58-62)$. Fakat otoinflamasyonu önleyici amaçla kullanılan endikasyonları ile ilgili veriler henüz sınırlı ve tartışmaya açıktır. Çünkü bazı otörler otoimmun hastalık varlığında PRP uygulamamaktadır (20).Plateletten zengin plazma otolog olması ile önemli avantajlar sunarken, heterolog PRP'nin de enfeksiyonlar ve yan etkiler açısından güvenilir olduğu gösterilmiş, böylece PRP uygulamaları için yeni bir çalışma alanı oluşmuştur (63). İleriki yıllarda farklı endikasyonlarda farklı PRP türleri bilimsel çalışmalarla karşılaştırılabilecektir.

Kozmetik dermatoloji dışındaki dermatolojik hastalıklarda PRP kullanımı görece yeni bir alan olup çalışma sonuçlarının ve meta-analiz verilerinin günümüz dermatoloji pratiğine neler getirebileceği merak uyandırmaktadır. Çalışmalarda elde edilen sonuçlar umut vermekte ve her geçen gün yeni bir endikasyona işaret etmekle birlikte genellikle uygulama standardizasyonu ve hasta sayısının azlığı sınırlayıcı etkileri oluşturmaktadır (13-5). Günümüze kadar sadece yara iyileşmesi, androgenetik alopesi ve akne skarlarında meta-analiz verileri mevcuttur $(31,36,39)$. İleriki yıllarda da daha bir çok dermatozda olgu sunumu ve çalışmaların olacağı aşikardır, fakat bu verilere titizlikle yaklaşmak gerektiği unutulmamalıdır. PRP'nin kesin endikasyonlarını belirlemeden önce, uygulamaların standardizasyonu ve geniş hasta popülasyonları üzerinde yapılmış kontrollü çalışmalara ihtiyaç olduğunu düşünmekteyiz.

Çıkar Çatışması: Çalışmada herhangi bir çıkar çatışması yoktur.
Finansal Çıkar Çatışması: Çalışmada herhangi bir finansal çıkar çatışması yoktur.

Address correspondence to: Selami Aykut Temiz, Yunus Emre Mh., Necmettin Erbakan Üniversitesi, 42080 Meram, Konya Türkiye

Telefon: +03322236204

e-mail: aykutmd42@gmail.com

\section{KAYNAKLAR}

1. Machlus KR, Thon JN, Italiano JE. Interpreting the develop mental dance of the megakaryocyte: A review of the cellular and molecular processes mediating platelet formation. $\mathrm{Br} \mathrm{J}$ Haematol 2014;165(2):227-36.

2. De Pascale MR, Sommese L, Casamassimi A, et al. Platelet derivatives in regenerative medicine: An update. Transfus Med Rev 2015;29(1):52-61.

3. Kumaran MS. Platelet-rich plasma in dermatology: Boon or a bane. Indian J Dermatol Venereol Leprol 2014;80(1):5-14.

4. Ferrari M, Zia S, Valbonesi M, et al. A new technique for hemodilution, preparation of autologous platelet-rich plasma and intraoperative blood salvage in cardiac surgery. Int J Artif Organs 1987;10(1):47-50.

5. Dhillon RS, Schwarz EM, Maloney MD. Platelet-rich plasma therapy - future or trend? Arthritis Res Ther 2012;14(4):219.

6. Leo MS, Kumar AS, Kirit R, et al. Systematic review of the use of platelet-rich plasma in aesthetic dermatology. J Cosmet Dermatol 2015;14(4):315-23.

7. Gonshor A. Technique for producing platelet-rich plasma and platelet concentrate: Background and process. Int J Periodontics Restorative Dent 2002;22(6):547-57.

8. Mazzocca AD, McCarthy MBR, Chowaniec DM, et al. Platelet-rich plasma differs according to preparation method and human variability. J Bone Joint Surg Am 2012;94(4):30816.

9. Kevy SV, Jacobson MS. Comparison of methods for point of care preparation of autologous platelet gel. J Extra Corpor Technol 2004;36(1):28-35.

10. Dohan Ehrenfest DM, Rasmusson L, Albrektsson T. Classification of platelet concentrates: From pure plateletrich plasma (P-PRP) to leucocyte- and platelet-rich fibrin (L-PRF). Trends Bio technol 2009;27(3):158-67.

11. Dhurat R, Sukesh M S. Principles and methods of preparation of platelet-rich plasma: A review and author's perspective. J Cutan Aesthet Surg 2014;7(4):189-97.

12. Welsh WJ. Autologous platelet gel: Clinical function and usage in plastic surgery. Cosmetic Derm 2000;11:13-9.

13. Sweeny J, Grossman BJ. Blood collection, storage and component preparation methods. In: Brecher $\mathrm{M}$, editor. Technical Manual. 14th ed. Bethesda MD: American Association of Blood Banks (AABB) 2002;955-8.

14. Scherer SS, Tobalem M, Vigato E, et al. Non-activated versus thrombin-activated platelets on wound healing and fibroblast-to-myofibroblast differentiation in vivo and in vitro. Plast Reconstr Surg 2012;129(1):46e-54e.

15. Marx RE. Platelet-rich plasma: Evidence to support its use. J Oral Maxillofac Surg 2004;62(4):489-96.

16. Gökdemir G. Mesotherapy and platelet-rich plasma for the treatment of hair loss. Turkderm 2014;48:Özel Sayı1:74-9.

17. Altuntaş Z, Gündeşlioğlu AÖ, İnce B, et al. Trombositten zengin plazma, trombositten fakir plazma, trombositten 
zengin fibrin kavramları, yara iyileşmesindeki biyolojik rolleri ve plastik cerrahide kullanım alanları. Turk J Plast Surg 2014;22(2):49-53.

18. Arora NS, Ramanayake T, Ren YF, et al. Platelet rich plasma: A literature review. Implant Dent 2009;18(4):303-10.

19. Lacci KM, Dardik A. Platelet-rich plasma: Support for its use in wound healing, Yale J Biol Med 2010;83(1):1-9.

20. Turan $A Y$, Erbil $H$, Koç E. Plateletten zengin plazma ve dermatoloji. Dermatoz 2011;2(3):355-60.

21. Gentile P, Garcovich S. Advances in regenerative stem cell therapy in androgenic alopecia and hair loss: Wnt pathway, growth-factor, and mesenchymal stem cell signaling impact analysis on cell growth and hair follicle development. Cells 2019;8(5),466.

22. Koç $E$, Şahan A. Kozmetik dermatolojide plateletten zengin plazma ile kombinasyon tedavileri. Turkiye Klinikleri Journal of Cosmetic Dermatology Special Topics 2014;7(3),20-4.

23. Hom DB. New developments in wound healing relevant to facial plastic surgery. Arch Facial Plast Surg 2008;10(6):4026.

24. Colletti T. Platelet-rich plasma: Effective treatment for sports injuries? J Musculoskel Med 2011;28(5):185-9.

25. Yildirim MEC, Ince B, Uyanik $O$, et al. Development of hyperalgesia in patients treated with autologous platelet rich plasma due to androgenetic alopecia. Selcuk Med J 2018;34(3):90-3.

26. Yol S, Tekin A, Yilmaz H, et al. Effects of platelet rich plasma on colonic anastomosis. J Surg Res 2008;146(2):190-4.

27. Man D, Plosker H, Winland Brown JE. Theuse of autologous platelet rich plasma (Platelet Gel) and autologous platelet poor plasma (Fibrin Glue) in cosmetic surgery. Plast Reconstr Surg 2001;107(1):229237.

28. Eppley BLMD, Woodell JE, Hıggıns JBS. Platelet quantification and growth factor analysis from platelet rich plasma: Implications for wound healing. Plast Reconstr Surg 2004;114(6):15021508.

29. Saad Setta H, Elshahat A, Elsherbiny K, et al. Platelet-rich plasma versus platelet-poor plasma in the management of chronic diabetic foot ulcers: A comparative study. Int Wound J 2011;8(3):307-12.

30. Antunes MB, Costa L, Carneiro M, et al. Topic platelet gel application in chronic diabetic foot ulcers. Diabetes\&Metabolic Syndrome: Clinical Research\&Reviews 2019;13(1):644-7.

31. Martinez-Zapata MJ, Martí-Carvajal AJ, Solà I, et al. Autologous platelet-rich plasma for treating chronic wounds. Cochrane Database Syst Rev 2016;5:006899.

32. Ince $B$, Yildirim MEC, Dadaci $M$, et al. Comparison of the efficacy of homologous and autologous platelet-rich plasma (PRP) for treating androgenic alopecia. Aesthetic Plast Surg 2018;42(1),297-303.

33. Schiavone G, Raskovic D, Greco J, et al. Platelet rich plasma for androgenetic alopecia: A pilot study. Dermatol Surg 2014;40(9):1010-9.

34. Gkini MA, Kouskoukis AE, Tripsianis G, et al. Study of plateletrich plasma injections in the treatment of androgenetic alopecia through an one-year period. J Cutan Aesthet Surg 2014;7(4):213-9.

35. Rose PT. The latest innovations in hair transplantation. Facial Plast Surg 2011;27:366-77.

36. Lotti T, Goren A, Verner I, et al. Platelet rich plasma in androgenetic alopecia: A systematic review. Dermatol Ther 2019;32(3),e12837.
37. Redaelli A, Romano D, Marcianó A. Face and neck revitalization with platelet-rich plasma (PRP): Clinical outcome in a series of 23 consecutively treated patients. J Drugs Dermatol 2010;9:466-72.

38. Asif M, Kanodia S, Singh K. Combined autologous plateletrich plasma with microneedling verses microneedling with distilled water in the treatment of atrophic acne scars: A concurrent split-face study. J Cosmetic Dermatol 2016;15(4):434-43.

39. Alser $\mathrm{OH}$, Goutos I. The evidence behind the use of plateletrich plasma (PRP) in scar management: A literature review. Scars Burn Heal 2018;4,2059513118808773.

40. Yuksel EP, Sahin G, Aydin F, et al. Evaluation of effects of platelet-rich plasma on human facial skin. J Cosmet Laser Ther 2014;16(5):206-8.

41. Shin MK, Lee JH, Lee SJ, et al. Platelet-rich plasma combined with fractional laser therapy for skin rejuvenation. Dermatol Surg 2012;38(4):623-30.

42. Gawdat HI, Hegazy RA, Fawzy MM, et al. Autologous platelet rich plasma: Topical versus intradermal after fractional ablative carbondioxide laser treatment of atrophic acne scars. Dermatol Surg 2014;40(2):152-61.

43. Gupta AK, Carviel J, Abramovits W. Treating alopecia areata: Current practices versus new directions. Am J Clin Dermatol 2017;18(1):67-75.

44. Trink A, Sorbellini E, Bezzola P, et al. A randomized, doubleblind, placebo- and active-controlled, half-head study to evaluate the effects of platelet-rich plasma on alopecia areata. Br J Dermatol 2013;169(3):690-4.

45. Kim DS, Park SH, Park KC. Transforming growth factor-beta 1 decreases melanin synthesis via delayed extracellular signal-regulated kinase activation. Int J Biochem Cell Biol 2004;36(8):1482-91.

46. Chatterjee $M$, Vasudevan $B$. Recent advances in melasma. Pigment International 2014;1(2),70-80.

47. Mahajan $\mathrm{R}$, Ninama $\mathrm{K}$, Shah $\mathrm{H}$, et al. Effect of intralesional platelet rich plasma in chronic localized vitiligo. Int J Res Dermatol 2018;4:550-5.

48. Hofny ER, Abdel-Motaleb AA, Ghazally A, et al. Plateletrich plasma is a useful therapeutic option in melasma. $\mathrm{J}$ Dermatolog Treat 2018;1-6.

49. Alam M, Hughart R, Champlain A, et al. Effect of plateletrich plasma injection for rejuvenation of photoaged facial skin: A randomized clinical trial. JAMA Dermatology 2018;154(12):1447-52.

50. Kim IS, Park KY, Kim BJ, et al. Efficacy of intradermal radiofrequency combined with autologous platelet-rich plasma in striae distensae: A pilot study. Int J Dermatol 2012;51(10):1253-8.

51. Suh DH, Lee SJ, Lee JH, et al. Treatment of striae distensae combined enhanced penetration platelet-rich plasma and ultrasound after plasma fractional radiofrequency. J Cosmet Laser Ther 2012;14(6):272-6.

52. Ibrahim ZAES, El-Tatawy RA, El-Samongy MA, et al. Comparison between the efficacy and safety of platelet-rich plasma vs. microdermabrasion in the treatment of striae distensae: Clinical and histopathological study. J Cosmet Dermatol 2015;14(4):336-46.

53. Gamil HD, Ibrahim SA, Ebrahim HM, et al. Platelet-rich plasma versus tretinoin in treatment of striae distensae: A comparative study. Dermatol Surg 2018;44(5):697-704.

54. Lim HK, Sh MK, Lee MH. Clinical application of PRP in 
vitiligo: A pilot study. Official 1st International Pigment Cell Conference 2011.

55. Ilbrahim ZA, El-Ashmawy AA, El-Tatawy RA, et al. The effect of platelet-rich plasma on the outcome of short-term narrowband-ultraviolet B phototherapy in the treatment of vitiligo: A pilot study. J Cosmet Dermatol 2016;15(2):108-16.

56. Kadry M, Tawfik A, Abdallah N, et al. Platelet-rich plasma versus combined fractional carbondioxide laser with plateletrich plasma in the treatment of vitiligo: A comparative study. Clin Cosmet Investig Dermatol 2018;11:551-9.

57. EL-Komy MHM, Hassan AS, Raheem HMA, et al. Plateletrich plasma for resistant oral erosions of pemphigus vulgaris: A pilot study. Wound Repair Regen 2015;23(6):953-5.

58. EL-Komy MHM, Saleh NA, Saleh MA. Autologous platelet-rich plasma and triamcinolone acetonide intralesional injection in the treatment of oral erosions of pemphigus vulgaris: A pilot study. Arch Dermatol Res 2018;310(4):375-81.

59. Merigo E, Oppici A, Parlatore A, et al. Platelet-rich plasma (PRP) rinses for the treatment of non-responding oral lichen planus: A case report. Biomedicines 2018;6(1):15.
60. Bolanča Ž, Goren A, Getaldić-Švarc B, et al. Platelet-rich plasma as a novel treatment for lichen planopillaris. Dermatol Ther 2016;29(4):233-5.

61. Goldstein AT, Mitchell L, Govind V, et al. A randomized double-blind placebo controlled trial of autologous platelet rich plasma intradermal injections for the treatment of vulvar lichen sclerosus. J Am Acad Dermatol 2019;80(6):1788-9.

62. Chakravdhanula U, Anbarasu K, Verma VK, et al. Clinical efficacy of platelet rich plasma in combination with methotrexate in chronic plaque psoriatic patients. Dermatol Ther 2016;29(6):446-50.

63. Abegão KGB, Bracale BN, Delfim IG, et al. Effects of heterologous platelet-rich plasma gel on standardized dermal wound healing in rabbits. Acta cirúrgica brasileira 2015;30(3):209-15. 